\title{
ICTs and Opinion Expression: An Empirical Study of New-Generation Migrant Workers in Shanghai
}

\author{
Baohua Zhou
}

This chapter focuses on the opinion expression of new-generation migrant workers and empirically examine its relationship with ICTs in China. It differentiates two kinds of problems that the migrant workers encounter, labour rights problems and personal emotion problems, as well as three types of expressive channels, interpersonal networks, new media, and institutional channels. By analysing the data from a questionnaire survey conducted in Shanghai of China $(N=869)$, we find that when faced with realistic problems, the intention of expression among newgeneration migrant workers is relatively high on the whole. In terms of expressive channels, they would like to express more via interpersonal network, followed by new media channels, and least via institutional channels. The online news and online interaction have been found to be significantly related to the expressive intention through new media, although they have no direct impact on offline expression. We conclude this chapter by discussing the academic and practical implications of this study.

\section{Introduction}

How should we make sense of Information and Communication Technologies' (ICTs) impact on society? An important approach is to empirically examine whether ICTs are empowering powerless groups. Empowerment is an enduring theme in Information and Communication Technology for Development (ICT4D) studies which refers to "the process through which individuals perceive that they control situations" (Rogers and Singhai 2003: p. 67). Scholars believe that ICTs can help

\footnotetext{
B. Zhou $(\square)$
}

School of Journalism, Fudan University, Shanghai, China

e-mail: zhoubaohua@yeah.net

A. Chib et al. (eds.), Impact of Information Society Research in the Global South, DOI 10.1007/978-981-287-381-1_14 
powerless, disabled, or marginalised groups in society to gain more opportunities to resolve personal and collective problems, to participate in decisions that affect their lives, and finally to earn control of their own lives (Elijah and Ogunlade 2006; Green 2008). By conducting empirical studies among women, farmers, poor, and other grass roots in the developing world, scholars have explored issues such as how the development and access to low-cost ICTs enhances access to accurate and reliable information for the poor (Elijah and Ogunlade 2006); how acquiring ICTs skills increases women's confidence, general knowledge, as well as knowledge of their rights (Green 2008); how ICTs can assist women in addressing the chronic issues of widespread poverty (Elijah and Ogunlade 2006); and how engagement with ICTs empowers grass roots to facilitate their civic engagement (Kwon and Nam 2009; Leung 2009), among others. Even so, a less studied issue concerning the empowerment role of ICTs is whether new technologies could help the marginalised group to voice themselves when they are faced with actual problems in their working and living situations.

The current study will address this question by examining the status of opinion expression of new-generation migrant workers in China and its relationship to ICTs. New-generation migrant workers, referring to those young rural-urban migrant workers aged under 30 who differ from their parents in their lack of farmer experience, low intention to return to home villages, and increasing reliance on ICTs, are typically marginalised people in post-reform China. This happens because they are poor, lack equal social welfare, are excluded by urban society, and are without significant power over their lives despite of their contributions to China's urbanisation. Compared to other social strata, new-generation migrant workers have less opportunities and skills to express their opinions in a traditional media environment, because they are inaccessible to such marginalised groups. Then, will new ICTs empower new-generation migrant workers by facilitating their intention to express their opinions via new media channels? Will expression via new media channels further encourage them to express via other channels such as interpersonal network or official institutions? These questions deserve careful empirical studies. Here, we treat facilitating opinion expression as one important dimension of empowerment of ICTs for migrant workers in China.

This chapter begins with literature review on the realistic needs of migrant workers, the expressive behaviours in the Chinese context, and the role of the Internet in facilitating opinion expression. Based on the discussions, we develop a set of specific hypotheses and research questions. Next, we quantitatively test our theoretical propositions with the data from a questionnaire survey we conducted in Shanghai of China. We conclude this chapter by discussing the implications of the research findings for academic research, governmental innovation, and corporation co-operations. 


\section{Literature Review}

\subsection{Realistic Needs ${ }^{1}$ of Migrant Workers}

Although the expression of opinion is conceived as the most basic form of political participation, prior empirical studies have showed that, in general, ordinary Chinese people are not active in expressing their opinions, especially in the public space, mostly due to the strict political control and low political efficacy (Pan et al. 2010; Chan and Zhou 2011). While scholars also argue that when people encounter realistic needs to resolve existential problems such as pollution in their living environment, their intention to engage in expressive behaviours would be higher (Yang 2009; Zhou 2011). So when studying the expression of migrant workers in China, it is better to examine the expressive intentions when they are faced with realistic needs or existential problems.

To focus on the realistic needs of migrant workers is also responding to the call for attention to the concept of "needs" in the ICTD research or "southern" communication studies. As Qiu (2010) put it, it is imperative for "southern" communication studies to tackle issues of needs (versus wants). "Needs" are basic resources or fundamental problem-resolving demands to help ordinary people especially marginalised groups to survive in the living world, to address issues such as job seeking, housing, education, health care, and social networking, while "wants" refer to those perceptions promoted by advertising and marketing campaigns, imposed by peer group pressure, and internalised as one's personal wants for "modern life" and "urban style", such as conspicuous consumption (Fitzgerald 1977). Following this conceptual distinction, Qiu (2009) argues that the most fundamental force to drive the information have less to adopt, and the use of new media technologies is the bottom-up needs of these marginalised people to deal with the existential issues created by the transformations of Chinese society, exacerbated by existing structural inequalities. The rise of working-class network society in China is, in this sense, a grounded transformation consisting of daily struggles by members of the have-less people to use working-class ICTs as micro-solutions to meet their needs at the grass-roots level. Hence, it is important to explore whether and to what extent migrant workers will voice themselves when they are faced with realistic problems.

What then are the main needs or realistic problems of new-generation migrant workers in the contemporary China? Prior empirical investigations, albeit limited in number, have showed two lines of them: one is the labour rights protection and the other is personal emotion problems (Chinese National Labour Union 2010; Wang and Chen 2012). The labour right protection problems refer to those problems that they are faced during the working process, including excessive working time, delay in paying, and working-related injury or illness. The personal emotion problems

\footnotetext{
${ }^{1}$ By "realistic needs", we emphasise that these needs are not "pseudo-needs" constructed by other social forms, such as the government or mass media, but stated by migrant workers themselves.
} 
include emotional confusion, loneliness, and monotony, which are the most serious problems facing migrant workers when they live in cities without their traditional emotional support from their families and relatives. Based on the discussion, we propose the first research question:

RQ1: What's the pattern of expressive intention among new-generation migrant workers when they are faced with realistic problems?

Since the labour rights protection problems are more basic and crucial for migrant workers to stay in the cities compared with personal emotion problems, we hypothesise that:

H1: The expressive intention will be higher when migrant workers are faced with labour rights problems than with personal emotion problems.

\subsection{Three Spaces of Opinion Expression in the Chinese Context}

Citizens can express their opinions in different social spaces or via different channels. In the context of transformational Chinese society, scholars have conceptualised three distinct spaces of expression based on activity contexts, corresponding venues, and felt inhibitory forces: face-to-face interpersonal private space, institutional space, and hybrid new media space, referring to the Internet and mobile phones (Pan et al. 2010; Chan and Zhou 2011). The idea of expressive space comes from what Zhou (2000: p. 604) refers to as the "discourse universe". In a study of how Chinese journalists engage in duplicity with official ideology, Zhou (2000) identifies two distinct universes of discourse: (1) the public discourse made up of discursive activities in the mass media, public meetings, and other institutionalised settings and (2) the private discourse comprised of information communicated through personal networks. In the Chinese context, the former universe is inclined towards the official sphere while the latter is nonofficial in nature (Zhou 2008). According to Habermas (2002), the distinction between the private and public spheres is also marked by a set of communicative conditions. People's experiences are first interpreted "privately" within the networks of interaction found in families, circles of friends, neighbours, colleagues, and acquaintances before being articulated and expressed in the public realm. In other words, the expression of opinion in private space is much more convenient and requires the least resources. For migrant workers, when they are faced with realistic problems in their work or life, it is natural to expect that they will first express their opinions in their personal networks. Although they may receive strategic or emotional support from their family members or close friends, they will not get substantive solutions from a discussion with them since most of the power and resources for problem-resolving have been strictly controlled by institutions such as governments or employers. 
Ironically, although theoretically it is more efficient to express opinions to official institutions for help, people seldom do so (Chan and Zhou 2011). Besides the more strict restriction and higher engagement cost, another important explanation is the lack of effective responses from the institutions. The official institutions such as the Labour Union are more like channels for propaganda, education, and social networking than for workers' rights protection, organisation, and participation (Hong 2003). As for the government's reaction, most of the complaints from the public never get responded. Wang (1997) found that only $1 \%$ of the complaints sent by mails were replied by the governments. The situation is even worse for migrant workers since they are among the highly oppressed and marginalised groups in the stratified Chinese society. The lack of economic, social, and cultural capital has made them almost invisible in the real-life public sphere (Qiu 2009; Zhao 2008).

Under such circumstances, the Internet becomes a new expressive space for marginalised groups to voice themselves (Mitra 2001, 2004). Thanks to the technical advantages, the Internet, especially Web 2.0 featuring the user-generated content (UGC), has for the first time provided a platform for the marginalised people to express themselves and participate in politics (Mehra et al. 2004; Zheng 2008). There is no question that the Chinese Internet is subject to tight regulations which bar negative references to the top leadership, the legitimacy of the Chinese Communist Party (CCP), and other politically sensitive issues (Sohmen 2001). Nevertheless, it is fair to say that cyberspace is much more liberal than the statecontrolled mass media and has raised opinion expression to an unprecedented level (Goldman 2005; Zheng 2008; Yang 2009). With the rapid expansion of the Internet across various social strata, it also gained a striking penetration among the group of new-generation migrant workers. Rather than "information have-nots", newgeneration migrant workers have actively adopted and used ICTs, being capable of interacting with digital media, integrating them into their modes of communication and ways of life, and even domesticating ICTs to meet their needs and resolve their existential problems (Peng 2008; Lin and Tong 2008; Qiu 2009). In this sense, they are "information have-less". An earlier survey conducted in Shanghai found that $75.4 \%$ of new-generation migrant workers are Internet users, among whom $74.5 \%$ are reading bulletin board system (BBS), $65 \%$ are posting messages on BBS or online forums, $76.4 \%$ are reading blogs (including microblogs), and $65 \%$ of them are writing their personal blogs or microblogs (Zhou and Lu 2011). This shows that in addition to being a convenient tool for migrant workers to access news online, the Internet has also become a site for their potential opinion expression, although there are no systematic empirical studies on the opinion expression among Chinese new-generation migrant workers until now, especially those studies focusing on the situation when they encounter realistic problems. More importantly, it deserves the examination of the emerging role of the Internet for the migrant workers' expression in the structure of three distinctive expressive spaces in China. Since the new media space was less restrictive than the institutional space but more restrictive than the interpersonal space, we propose the following hypothesis: 
H2: When migrant workers are faced with realistic problems, they will be more likely to express their opinions via new media channels than institutional channels (H2a), though their expressive intentions in personal networks are still highest (H2b).

It should be noted that this study focused on expressive intentions rather than actual expressive behaviours, given that Chinese people in general seldom express themselves especially in the public space. Expressive intention is argued to be the most robust predictable variable for actual expressive behaviours (Fishbein and Ajzen 1975); hence, we adopted expressive intention measures as a proxy for real behaviour.

\subsection{Factors Influencing Opinion Expression and the Role of the Internet}

The extant literature based primarily on the evidence from developed democracies and upper-middle class in Chinese society suggests four basic sets of predictors of citizens' expressive engagement in public life: (1) the socio-demographic variables that index individuals' possession of material and, indirectly, social as well as expressive competence resources, (2) the psychological variables that index individuals' interest in public life and their attitudes towards involvement, (3) social interaction and social networking variables that index individuals' possession of social capital and placement in the social ecology that facilitate their engagement, and (4) media use and other communicative activities that index individuals' interactions with their information environment, which can be viewed both as a constituting part of individuals' engagement and a key venue to prepare them for engagement in other forms (e.g. Delli Carpini 2004; Jacobs et al. 2009; Verba et al. 1995; Lei 2011; Shen et al. 2009; Shyu 2009).

We argue that these factors are also important to influence the expressive intentions of new-generation migrant workers. First, we expect individual migrant workers to show higher levels of expressive engagement if they possess more material resources. As scholars have noticed (e.g. Qiu 2009; Zhou and Lu 2011), the issue of internal stratification or variation among migrant workers has been ignored in the extant literature. Although migrant workers could be treated and analysed as a group, when they are compared with other groups with higher socioeconomic status (SES), they are not a single homogeneous group in terms of their socioeconomic positioning and ICT connectivity. Instead, there is a significant internal variation and in-group stratification in terms of gender, education, income, profession, and ownership of employers. ${ }^{2}$ How these internal variations influence their expressive

\footnotetext{
${ }^{2}$ The ownership of employers includes three models: state-owned, private-owned, and overseas investment (investment from Hong Kong, Macau, and Taiwan included).
} 
intentions will be empirically examined in this study. Second, we expect those migrant workers perceiving greater seriousness of the problems they encounter and having higher levels of political efficacy to be more likely to express their opinions. Third, social networking and social capital are important resources for migrant workers to engage in expressive behaviours. Based on case studies, scholars (e.g. Guo et al. 2011) have argued that whether having everyday social network influences the action models of migrant workers when they are faced with serious problems, in the "atomized" situation where the primary social network is missing, they tend to resort to personal solutions such as suicide; the existence of social network (e.g. the hometown fellow organisations) will facilitate them to organise and take collective actions to protect their own rights. Therefore, whether having supporting social networks plays a critical role in influencing migrant workers' expressive intentions, carrying out broader and more frequent social interactions with others will positively relate to their opinion expression. Fourth, as an important information resource, news media use is expected to facilitate expressive behaviours of migrant workers.

The Internet has been viewed in a similar way. Scholars have argued that the Internet may contribute to citizens' expressive engagement because of its abundant and diverse information, open and democratic discussion, and "horizontal communication" (Polak 2005; Hung 2006; Shirk 2007). Empirically, in a metaanalysis of 38 studies with 166 effect estimates, Boulianne (2009) reports that online news use had significant positive effects on citizenship engagement. In China, the Internet has also been found to be positively related to engagement in general. For example, Lei (2011) showed using the 2007 World Value Survey Data that compared with exclusive traditional media users and non-media users, Chinese netizens were more likely to be opinionated, more likely to be "politicised"- that is, simultaneously embracing the norms of democracy and being critical of the current political conditions and the party-state-and more likely to have experiences in collective action. Chan and Zhou (2011) show Internet news use had significantly positive influence on opinion expression in the new media space, though it had no significant effect on offline expression.

Following these theoretical arguments, we expect that the Internet also has potential to facilitate expressive intentions among new-generation migrant workers via various processes. First, as a source for abundant and diverse information, the Internet can facilitate steady and fuller information flows which serves as the basic resources for migrant workers to express their opinions. For example, when they are faced with labour protection problems, they can easily find useful information online which can help them to express their opinions with more knowledge and confidence. Second, the Internet can serve as an openly accessible virtual space for migrant workers to interact with others and organise to voice their own opinions. Scholars have argued that the Internet becomes an important space for migrant workers to interact with each other and to maintain and extend their social networks (Law and Chu 2008; Lin and Tong 2008), which can make expression much easier, be it labour issues or emotional issues. Third, both the information acquisition and interpersonal interactions via the Internet may facilitate their offline expression. Online expression is actually an exercise for marginalised people to engage in public affairs, and this 
kind of exercise might even ease the fear about expression in public sphere. In other words, the Internet has the potential to encourage migrant workers to speak out when they are faced with realistic problems. Thus we will test the following hypothesis:

H3: The Internet use (e.g. online news use and communicative use) is positively related to the levels of expressive intention of new-generation migrant workers.

In addition, we tested if each of the following factors, higher socioeconomic status, perceived problem seriousness, political efficacy, social interactions, and news media use, is positively related to the levels of expressive intention of newgeneration migrant workers.

\section{Method}

\subsection{Survey}

The data came from a survey of new-generation migrants conducted in Shanghai. To improve the representativeness of the sampling, this study sampled based on two variables-industry (manufacturing, construction, and service) and ownership of their workplace (state-owned, private-owned, and overseas investment including those from Hong Kong, Macau, and Taiwan). Firstly 13 companies $^{3}$ were selected as survey locations. At each selected location, we conducted either census survey (if there were 100 or less than 100 migrant workers in the selected company) or systematic random sampling survey (if there were more than 100 migrant workers in the selected company) on migrant workers aged from 16 to 30 . By conducting self-administered questionnaire survey, we collected 1,000 questionnaires among which 869 were fully completed, which amounted to a response rate of $86.9 \%$.

\subsection{Measures}

Dependent variable: Expressive intentions. The respondents were asked to indicate how likely $(1=$ absolutely will not, $5=$ absolutely will $)$ they will express their opinions or appeals in each of the three types of channel (personal network, new media, and institutional) when they are faced with labour rights problems or

\footnotetext{
${ }^{3}$ Among them, seven are manufacturing companies, four are service, and two are construction ones. Three are state-owned, six are private, and four are overseas investment. They were chosen based on personal network. Although it is difficult to assess the accurate representativeness of this sample because of the lack of a census of new-generation migrant workers in Shanghai, the sample did show a sound representativeness by this stratified sampling design. Please refer to the demographics section for reference.
} 
personal emotion problems. Separate factor analyses of 13 items measuring the respondents' expressive intentions under each problem domain were conducted, and each resulted in the following three factors as expected: expressive intentions via personal network (including discussion with family members and friends, workmates, or fellow townsmen), new media channels (including posting comments on the online forums or communities, on the blogs, on the QQ/MSN group, talking with friends on QQ/MSN, and sending or forwarding comments via SMS), and institutional channels (reporting to traditional media, employers, the Labour Union or the Youth League, government departments, and social organisations). An index of expressive intentions via each channel was subsequently created by averaging the scores among the items contained within this factor to represent the level of opinion expression concerning each problem (Cronbach's alpha ranged from .82 to .92).

Independent variables include:

Demographics We measured the following demographical variables: gender (male $=59.1 \%)$, age $(M=23.2, \mathrm{SD}=3.5)$, education $(45.7 \%$ of the respondents graduated from high school, followed by junior high school with $25.9 \%$ ), average monthly income (36.8\% ranged from 1,501 to 2,000 RMB and $24.1 \%$ ranged from 1,001 to $1,500 \mathrm{RMB}$ ), industry (manufacturing $=47.2 \%$, construction $=25.7 \%$, service $=27.1 \%$, and ownership of their workplace $($ state-owned $=24.6 \%$, private-owned $=35.3 \%$, and overseas investment $=30.1 \%$ ).

Perceived Seriousness Five items were used to measure the perceived seriousness of the labour rights problems and personal emotional problems the migrant workers came across $(1=$ almost no, $5=$ very serious $)$. The former included excessive working time, delay in paying, and working-related injury or illness $(\alpha=.73)$. The latter included emotional confusion, loneliness, and monotony $(\alpha=.76)$.

Political Efficacy Respondents were asked to what extent they agreed to the following four statements $(1=$ strongly disagree, $5=$ strongly agree $)$ : "I have clear understanding of the problems that should be settled by the governmental policy"; "I'm able to make constructive suggestions on the policies and decisions of the government"; "every citizen like me can influence the policies and decisions of the government"; and "the government responds to the suggestions of citizens properly". Factor analysis showed only one factor indicating that new-generation migrant workers had no clear awareness of discriminating two aspects of political efficacy - internal efficacy and external efficacy — which are often distinguished in the related literature. Therefore, we averaged the scores among the items to represent the political efficacy $(\alpha=.81, M=2.69, \mathrm{SD}=.75)$.

Social Network Eight questions were asked about how often $(1=$ almost not, $5=$ very often) do new-generation migrant workers have contact with the following four groups in their work and life: fellow townsmen, migrant workers from other towns, local Shanghainese, and leaders or bosses of the workplace. Factor analysis was then conducted and resulted in two factors as expected: the homogeneous network (contacting with fellow townsmen and workmates; $\alpha=.77$, $M=3.47, \mathrm{SD}=.76$ ) and heterogeneous network (contacting with local people and leaders/bosses; $\alpha=.82, M=2.23, \mathrm{SD}=.85)$. 
Traditional Media Use Respondents were asked how closely $(1=$ almost no, $5=$ very closely) they paid attention to international, national, local, and hometown news, respectively. The four items for TV were averaged into an index $(\alpha=.74)$ and the four for newspaper were averaged into another $(\alpha=.70)$.

New Media Use Online news use was measured by averaging the scores of frequency $(1=$ never, $5=$ always when connected) of respondents' use of online domestic news, international news, local Shanghai news, and hometown news $(\alpha=.82)$. Online interaction was measured by averaging their frequency of using $\mathrm{QQ}$, other chat tools, and SMS ( $\alpha=.54)$. When analysing the expressive intentions via personal network and institutional channels, we averaged the two variables of online news use and online interaction to avoid the multicollinearity because of their high correlation $(r=.80, p<.001)$. It should be mentioned that we did not include the ownership of cellphone into our model as $96.0 \%$ of our samples own cellphones.

\section{Results}

\subsection{Perceived Problem Seriousness}

Firstly, we would like to report the basic situation of the problems that newgeneration migrants come across in Shanghai. The survey shows (Table 1) that $78.4 \%$ of new-generation migrant workers consider themselves to have encountered "a little" labour rights protect problems (among which the most serious one is excessive working time) and $91.4 \%$ of them think that they have "a little" personal emotion problems (the most serious one is monotony). These results illustrate that the two types of issues defined here are common and realistic problems facing this group. Paired sample $t$-test shows that personal emotion problems are significantly higher than labour rights problems $(t=13.0, p<.001)$.

Table 1 Basic situation of the problems that new-generation migrant workers come across

\begin{tabular}{l|l|l}
\hline & Mean $(\mathrm{SD})$ & $\begin{array}{l}\text { Percentage of at least } \\
\text { having "a little" }(\%)\end{array}$ \\
\hline Labour rights problems $(N=862)$ & $1.96(.85)$ & 78.4 \\
\hline Delay in paying & $1.51(.85)$ & 32.2 \\
\hline Working-related injury/illness & $1.87(1.01)$ & 51.6 \\
\hline Excessive working time & $2.49(1.26)$ & 73.4 \\
\hline Personal emotion problems $(N=858)$ & $2.41(.84)$ & 91.4 \\
\hline Emotional confusion & $2.29(.98)$ & 74.1 \\
\hline Loneliness & $2.33(1.01)$ & 76.3 \\
\hline Monotony & $2.62(1.05)$ & 84.6 \\
\hline
\end{tabular}




\subsection{Expressive Intentions}

We were interested in new-generation migrant workers' expressive intentions when they came across problems above $(R Q 1)$. Table 2 shows that when they come across labour rights problems, $90.5 \%$ will express via personal networks, $77.8 \%$

Table 2 Expressive intentions of new-generation migrant workers

\begin{tabular}{|c|c|c|c|c|}
\hline & \multicolumn{2}{|c|}{ Labour rights problems } & \multicolumn{2}{|c|}{ Personal emotion problems } \\
\hline & $\begin{array}{l}\text { Mean } \\
(\mathrm{SD})\end{array}$ & $\begin{array}{l}\text { Percentage of at } \\
\text { least "might do } \\
\text { occasionally" } \\
(\%)\end{array}$ & $\begin{array}{l}\text { Mean } \\
\text { (SD) }\end{array}$ & $\begin{array}{l}\text { Percentage of at } \\
\text { least "might do } \\
\text { occasionally" } \\
(\%)\end{array}$ \\
\hline Personal networks & $3.39(.92)$ & 90.5 & $2.98(1.00)$ & 79.3 \\
\hline $\begin{array}{l}\text { Discussion with } \\
\text { family members or } \\
\text { friends }\end{array}$ & $3.31(1.19)$ & 76.5 & $3.08(1.27)$ & 67.7 \\
\hline $\begin{array}{l}\text { Discussion with } \\
\text { workmates }\end{array}$ & $3.48(.98)$ & 87.1 & $2.91(1.10)$ & 67.8 \\
\hline $\begin{array}{l}\text { Discussion with } \\
\text { fellow townsmen }\end{array}$ & $3.37(1.04)$ & 82.9 & $2.95(1.13)$ & 68.2 \\
\hline New media & $2.48(.97)$ & 77.8 & $2.25(.92)$ & 72.0 \\
\hline $\begin{array}{l}\text { Posting on online } \\
\text { forums or } \\
\text { communities }\end{array}$ & $2.35(1.16)$ & 41.6 & $1.90(1.02)$ & 25.6 \\
\hline $\begin{array}{l}\text { Comment on the } \\
\text { blogs }\end{array}$ & $2.22(1.14)$ & 36.0 & $1.92(1.05)$ & 25.8 \\
\hline $\begin{array}{l}\text { Talking to friends via } \\
\text { QQ/MSN }\end{array}$ & $2.54(1.25)$ & 49.0 & $2.42(1.23)$ & 48.1 \\
\hline $\begin{array}{l}\text { Posting on QQ/MSN } \\
\text { group }\end{array}$ & $2.31(1.20)$ & 40.0 & $2.17(1.19)$ & 35.3 \\
\hline $\begin{array}{l}\text { Sending or } \\
\text { forwarding } \\
\text { comments via SMS }\end{array}$ & $2.94(1.23)$ & 63.3 & $2.82(1.25)$ & 60.6 \\
\hline Institutional channels & $2.28(.95)$ & 66.2 & $1.73(.82)$ & 35.1 \\
\hline $\begin{array}{l}\text { Reporting to } \\
\text { traditional media }\end{array}$ & $2.02(1.08)$ & 29.1 & $1.70(.92)$ & 18.2 \\
\hline $\begin{array}{l}\text { Communicating with } \\
\text { the employers }\end{array}$ & $2.58(1.17)$ & 53.0 & $1.80(.97)$ & 23.1 \\
\hline $\begin{array}{l}\text { Reporting to the } \\
\text { Labour Union or the } \\
\text { Youth League }\end{array}$ & $2.28(1.14)$ & 40.3 & $1.72(.89)$ & 19.2 \\
\hline $\begin{array}{l}\text { Reporting to related } \\
\text { government } \\
\text { department }\end{array}$ & $2.21(1.13)$ & 37.1 & $1.66(.92)$ & 17.3 \\
\hline $\begin{array}{l}\text { Reporting to other } \\
\text { social organisations }\end{array}$ & $2.23(1.11)$ & 39.3 & $1.75(.96)$ & 20.4 \\
\hline
\end{tabular}

Note: $N$ ranges between 830 and 861 . This table is compiled by the author 
would like to express via new media, and $66.2 \%$ choose to express through institutional channels. At the same time, when they are faced with personal emotion problems, $79.3 \%$ will express via personal networks, $72.0 \%$ would like to express via new media, and $35.1 \%$ choose to express through institutional channels. This indicates that the expressive intentions of new-generation migrant workers in Shanghai are relatively high when they come across realistic problems in work or life. Paired sample tests show that their expressive intentions when they are faced with labour rights problems are significantly higher than when they are faced with personal emotion problems $(t=13.0, p<.001$ [personal networks], $t=8.3$, $p<.001$ [new media], $t=18.0, p<.001$ [institutional channels]), although the perceived seriousness of the former is lower than the latter. This could be explained by two reasons: firstly, labour rights problems are more related to basic needs of migrant workers (e.g. health, the income to support a family); secondly, compared with personal emotion problems, labour rights problems are more public and easier to arouse sympathy and resonance; thus they are more proper to be discussed in the public sphere. H1 is thus supported.

In terms of expression channels, results show that the new-generation migrant workers are more willing to express through personal networks regardless of the type of problem they are facing. Expressive intentions through new media come next (the differences between these two channels are significant, $t=24.1$, $p<.001$ [labour rights problems], $t=19.0, p<.001$ [life and emotion problems]). Institutional channels take the last place (the differences between institutional channels and new media channels are also significant, $t=6.3, p<.001$ [labour rights problems], $t=17.6, p<.001$ [life and emotion problems]). It illustrates that when new-generation migrant workers come across realistic problems, they tend to turn to primary group and personal network for support. At the same time, new media is becoming a vital expression space which includes not only the interpersonal contact tools for long-distance interaction like QQ and cellphones, but also online forums, blogs, and QQ groups which are more public and have the potential to transform private expression into public expression. In contrast, new-generation migrant workers do not like to express opinions or ask for help through institutional channels, although many of their problems need to be settled by their company, Labour Union, and even the government. This pattern supports $\mathrm{H} 2$.

\subsection{Influencing Factors of Expressive Intentions}

We apply OLS regressions to analyse the influence of independent variables on the expressive intentions of new-generation migrant workers (Table 3). First of all, personal background has some impact on the expressive intentions. The major influences come from three variables_-gender (females are more likely to express personal emotion problems through personal networks than males while males are more inclined to express through institutional organisations), age (the elder are more willing to express personal emotion problems through personal networks), 


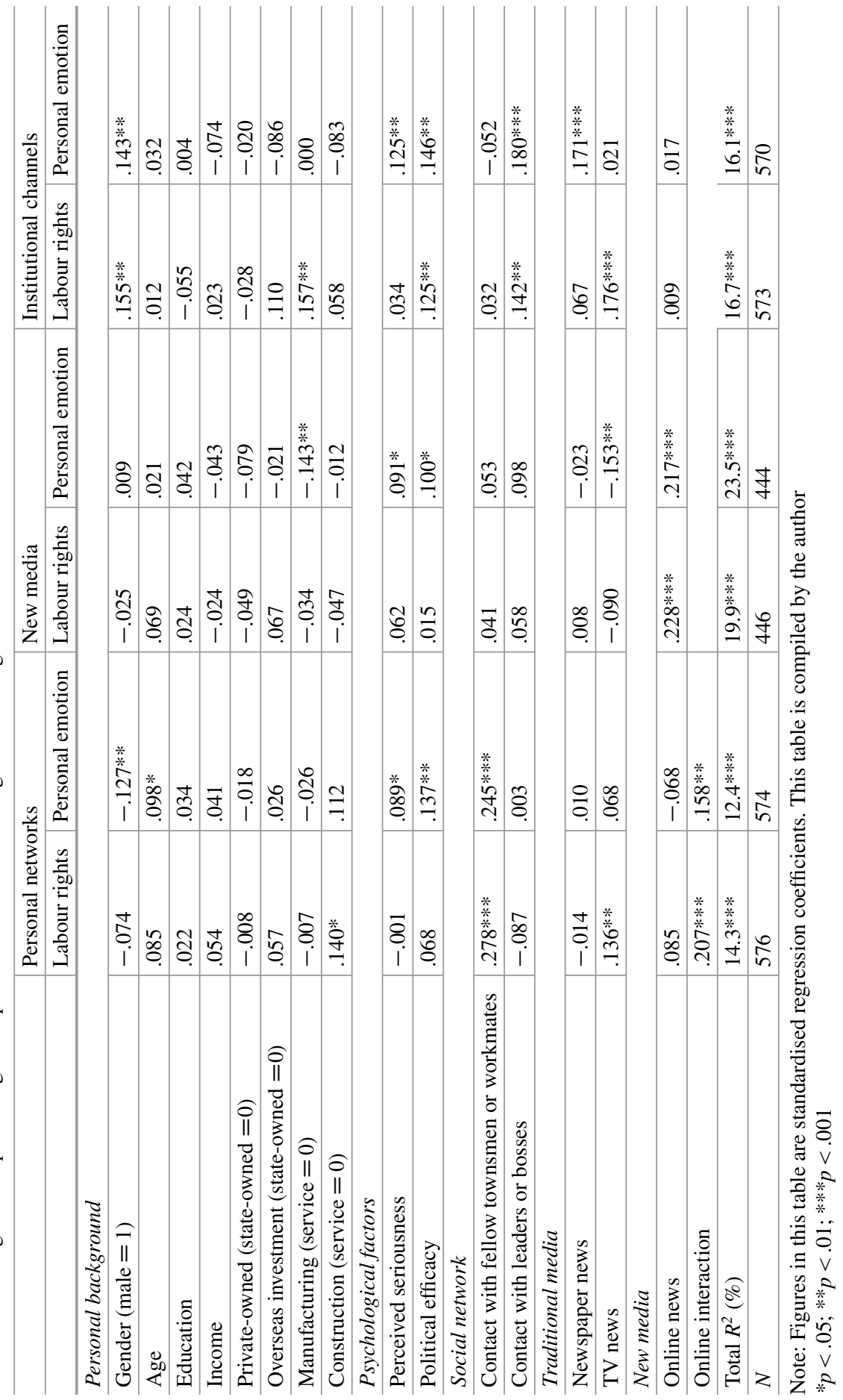


and industry (compared with workers of service industry, manufacturing industry workers express less personal emotion problems in the new media space while they assert more demands via the institutional channels about labour rights problems; construction industry workers discuss labour rights problems more often in the private space).

Secondly, psychological factors have significant impact on expressive intentions. Nevertheless, the impact of perceived seriousness differs from issue to issue-only significant with the personal emotion problems, while the perceived seriousness of labour rights problems has no significant influence on expression. The influence of political efficacy is also more powerful for personal emotion problems, though it has significant influence on the expressive intention through institutional channels when they are faced with labour rights problems $(\beta=.125, \mathrm{p}<.01)$.

Thirdly, the social network shows significant influence while mainly for expressive intentions through offline spaces. The more frequent the interaction with fellow townsmen or workmates, the stronger the intention to express through personal networks ( $\beta=.278, p<.001$ [labour rights], $\beta=.245, p<.001$ [life and emotion]). More frequent interaction with local Shanghainese or leaders and bosses promotes their intention to express through institutional channels $(\beta=.142, p<.001$ [labour rights], $\beta=.180, p<.001$ [life and emotion]).

Fourthly, TV news has stronger influence than newspaper-the latter only has significant influence on expression through institutional channels about personal emotion problems. It has significant influence on the expressive intention through both personal networks and institutional channels when they are faced with labour rights problems. This may be due to the higher frequency of TV news exposure $(M=2.44, \mathrm{SD}=1.63$, while for newspaper news, $M=1.18, \mathrm{SD}=1.69)$ and that watching TV is more like a kind of collective behaviour (this survey shows that $61.9 \%$ of migrant workers watch TV together) thus setting creating a space for them to communicate with each other, although more TV news use constrains their intentions to express personal emotion problems via new media.

Last but not least, when all other variables are controlled, online news and online interaction are still the major influencing factors of expressive intention via new media ( $\beta$ ranges from .158 to .228 and significantly at between .01 and .001 ). This illustrates that more Internet news browsing and more active Internet interaction encourage stronger intention to express their appeals via new media. Yet, consistent with previous studies (Chan, and Zhou 2011; Pan et al. 2010), no direct influence of the Internet use on offline expression is found in this study. H3 is thus partially supported.

\section{Conclusion}

The current study empirically investigates the intention of expression when faced with realistic problems among new-generation migrant workers in Shanghai. The main findings are as follows. 
First, when faced with realistic problems, the intention of expression among new-generation migrant workers in Shanghai is relatively high on the whole. Second, consistent with the general public, the expressive channels of this group decrease progressively in a way of "personal networks-new media-institutional channels". Third, internal diversity is found in the expression of new-generation migrant workers in terms of gender, age, and industry where they work. Fourth, the influence of psychological factors varies with issues-it only has significant influence on the intention of expression concerning personal emotion problems; psychological factors have little influence on expression of labour rights problems, except for the impact of political efficacy on expression via institutional channels. Fifth, social network is found to be a vital factor in the matter of offline expression in the way that homogeneous network (i.e. contact with fellow townsmen and workmates) facilitates expression through personal network while heterogeneous network (i.e. contact with local people and employers) facilitates expression via institutional channels. Sixth, exposure to TV news increases the likelihood of offline expression on labour rights problems. Lastly, online news and online interaction have significant impact on expression through new media but have no direct impact on offline expression.

Based on the above empirical findings, we could better understand the impacts and implications of the new media for the new-generation migrant workers in China. First, new media channels, including multiple online platforms and mobile phones, have become an important space for the migrant workers to voice themselves when they are faced with actual problems. Since expressive intention is believed to be the strongest predictor of real expressive behaviours according to the classic theory of reasoned action (Fishbein and Ajzen 1975), the higher expressive intention through new media channels could be transferred into their actual opinion expression through these platforms, which may have some potential for the marginalised group to change their personal as well as collective lives. In this sense, we could say that the Internet has the potential to empower the migrant workers in China in terms of making them and their lives more visible. Second, online news exposure and online interaction have been proven to have positive impacts on the expressive intentions among migrant workers, which show the significance of these two kinds of online behaviours. Our study also cautions that there are no direct linkages between ICTs use and offline expressive intentions, which suggests that more concrete actions should be taken to promote the online expressions to offline actions. In other words, the online activities should be combined with offline actions to improve the motivation for the migrant workers to voice themselves.

This study has implications for academia, policy, and practitioners. In terms of theoretical contributions, it is the first empirical study to examine the status of opinion expression among new-generation migrant workers and how it is influenced by various factors especially Internet use. By focusing on a specific social group, this study has confirmed the spatial structure of "personal networks-new mediainstitutional channels" for people to express opinions when they are faced with personal or social problems. It has also explicated the different influential patterns for two kinds of realistic needs-resolving labour rights problems and personal 
emotion problems - which suggest that they require different resources to facilitate expressive intentions. It has also shown that the Internet could empower migrant workers at least in two ways-as an expressive space itself and as a positive factor to encourage online expressions. Thus, this study endeavours to operationalise "empowerment" from the angle of opinion expression in the Chinese context.

For policymakers and social activists, they may obtain inspiration from these findings to consider designing effective campaigns via online platforms to facilitate the active opinion expression among Chinese new-generation migrant workers. For example, nowadays the Chinese government is launching a new campaign to promote "e-government". How can the migrant workers benefit from this campaign? Can they interact with governmental labour offices to protect their rights via "egovernment" social media such as Weibo or WeChat? Can their voices be heard by the government? Our study suggests that the government should make efforts to build online platforms for the migrant workers to express their opinions when they are faced with problems and develop an efficient system to receive and respond to these feedback. For the practitioners (i.e. online corporations), highly active opinion expression is a necessary foundation for the energy of the online community. Given that the number of new-generation migrant workers in China is huge, to build an online community for them to engage in expressive behaviours is very valuable. It is not only the social accountability of big companies but also a new opportunity for them to develop a booming online market.

This study is a quantitative study to show the basic pattern of migrant workers' expressive intentions and their influential factors. For the future studies, we suggest more empirical work, especially qualitative ones, could be done to further explicate the mechanism of how the Internet facilitates the migrant workers' expressive intentions.

Acknowledgements This chapter is supported by the SIRCAII project, Shanghai Social Science Foundation Project (\#2012BXW004) and Shanghai Pujiang Talents Program (\#13PJC020). The author wishes to thank Dr. Jack Linchuan Qiu for his valuable collaborations and suggestions during the whole research, and thank Arul Chib, Julian May, Roxana Barrantes, Ang Peng Hwa, and Roger Harris for their insightful comments on the earlier manuscript. The author also thanks two RAs Shuning Lu and Miao Xiao for their help in the fieldwork.

Open Access This chapter is distributed under the terms of the Creative Commons Attribution Noncommercial License, which permits any noncommercial use, distribution, and reproduction in any medium, provided the original author(s) and source are credited.

\section{References}

Boulianne, S. (2009). Does Internet use affect engagement? A meta-analysis of research. Political Communication, 26(2), 193-211.

Chan, J. M., \& Zhou, B. (2011). Expressive behaviors across discursive spaces and issue types. Asian Journal of Communication, 21(2), 150-166. 
Chinese National Labor Union. (2010, June 21). A research report on new generation migrant workers. Workers' Daily.

Delli Carpini, M. X. (2004). Mediating democratic engagement: The impact of communications on citizens' involvement in political and civic life. In L. L. Kaid (Ed.), Handbook of political communication research (pp. 395-434). Mahwah: Lawrence Erlbaum Associates.

Elijah, A. O., \& Ogunlade, I. (2006). Analysis of the uses of information and communication technology for gender employment and sustainable poverty alleviation in Nigeria. International Journal of Education and Development Using ICT, 2(3), 45-69.

Fishbein, M., \& Ajzen, I. (1975). Belief, attitude, intention and behavior: An introduction to theory and research. Reading: Addison-Wesley.

Fitzgerald, R. (1977). Human needs and politics. Sydney: Pergamon Press.

Goldman, M. (2005). From comrade to citizen: The struggle for political rights in China. Cambridge, MA: Harvard University Press.

Green, J. H. (2008). Measuring women's empowerment: Development of a model. International Journal of Media and Cultural Politics, 4(3), 369-389.

Guo, Y., Shen, Y., Pan, Y., \& Lu, H. (2011). The struggle of migrant workers and the transformational labor-capital relationship in contemporary China. 21th Century Review, 4, 4-14.

Habermas, J. (2002). Civil society and the political public sphere. In C. Calhoun, J. Gerteis, J. Moody, \& S. Pfaff (Eds.), Contemporary sociological theory (pp. 358-376). Oxford: Blackwell.

Hong, Y. (2003). On political efficacy in China. Academic Exploration, 7, $42-45$ (In Chinese).

Hu, R. (2008). Social capital and political participation in an urban city. Jounal of Sociology, 5, 142-159 (in Chinese).

Hung, C. F. (2006). The politics of cyber participation in the PRC: The implications of contingency for the awareness of citizens' rights. Issues and Studies, 42(4), 137-173.

Jacobs, L. R., Cook, F. L., \& Delli Carpini, M. X. (2009). Talking together: Public deliberation and political participation in America. Chicago: University of Chicago Press.

Kwon, K., \& Nam, Y. (2009). Instrumental utilization of ICTs in mobilization processes of political collective actions: In the context of grassroots protest of Korea 2008. Paper presented at the annual meeting of the International Communication Association (pp. 1-31), Chicago.

Law, P. L., \& Chu, W. C. R. (2008). ICTs and migrant workers in contemporary China. Knowledge Technology and Policy, 21(2), 43-45.

Lei, Y. W. (2011). The political consequences of the rise of the Internet: Political beliefs and practices of Chinese netizens. Political Communication, 28(3), 291-322.

Leung, L. (2009). User-generated content on the internet: An examination of gratifications, civic engagement and psychological empowerment. New Media and Society, 11(8), 1327-1347.

Lin, A., \& Tong, A. (2008). Mobile cultures of migrant workers in Southern China: Informal literacies in the negotiation of (new) social relations of the new working women. Knowledge Technology and Policy, 21(2), 73-81.

Mehra, B., Merkel, C., \& Bishop, A. P. (2004). The internet for empowerment of minority and marginalized users. New Media and Society, 6(6), 781-802.

Mitra, A. (2001). Marginal voices in cyberspace. New Media and Society, 3(1), 29-48.

Mitra, A. (2004). Voices of the marginalized on the internet: Examples from a website for women of South Asia. Journal of Communication, 54(3), 492-510.

Pan, Z., Jing, G., Yan, W., \& Zheng, J. (2010, June). Understanding expressive engagement in urban China: Differentiating domains, settings, and media effects. Paper presented at the annual conference of the International Communication Association, Singapore.

Peng, Y. (2008). Internet use of migrant workers in the Pearl River Delta. Knowledge Technology and Policy, 21(2), 47-54.

Polak, R. K. (2005). The Internet and political participation: Exploring the explanatory links. European Journal of Communication, 20(4), 435-459.

Qiu, J. L. (2009). Working-class network society: Communication technology and the information have-less in urban China. Cambridge, MA: MIT Press. 
Qiu, J. L. (2010). Southern imagination: Class, network, and communication. Chinese Journal of Communication Research, 12, 51-69.

Rogers, E., \& Singhai, A. (2003). Empowerment and communication: Lessons learned from organizing for social change. Communication Yearbook, 27, 67-86.

Shen, F., Wang, N., Guo, Z., \& Guo, L. (2009). Online network size, efficacy, and opinion expression: Assessing the impacts of Internet use in China. International Journal of Public Opinion Research, 21(4), 451-476.

Shirk, S. (2007). China: Fragile superpower. Oxford: Oxford University Press.

Shyu, H. (2009). Psychological resources of political participation: Comparing Hong Kong, Taiwan, and Mainland China. Journal of International Cooperation Studies, 17(2), $25-47$.

Sohmen, P. (2001). Taming the dragon: China's efforts to regulate the Internet. Stanford Journal of East Asian Affairs, 1, 17-26.

Verba, S., Schlozman, K. L., \& Brady, H. E. (1995). Voice and equality: Civic voluntarism in American politics. Cambridge, MA: Harvard University Press.

Wang, J. (1997). On government power. Beijing: China Fangzheng Publishing (In Chinese).

Wang, F., \& Chen, Y. (2012). From potential users to actual users: Use of e-government service by Chinese migrant farmer workers. Government Information Quarterly, 29, 98-111.

Yang, G. (2009). The power of the Internet in China: Citizen activism online. New York: Columbia University Press.

Zhao, Y. (2008). Communication in China: Political economy, power, and conflict. Lanham: Rowman \& Littlefield.

Zheng, Y. (2008). Technological empowerment: The Internet, state, and society in China. Stanford: Stanford University Press.

Zhou, H. (2000). Working with a dying ideology: Dissonance and its reduction in Chinese journalism. Journalism Studies, 1(4), 599-616. doi:10.1080/146167000441321.

Zhou, H. (2008). SMS in China: A major carrier of the nonofficial discourse universe. The Information Society, 24(3), 182-190. doi:10.1080/01972240802020101.

Zhou, B. (2011). Media exposure, civic participation and political efficacy: An empirical study on "Xiamen PX Event". Open Times, 5, 123-141 (In Chinese).

Zhou, B., \& Lu, S. (2011). An empirical study of ICTs and new generation migrant workers in Shanghai. Journalism Quarterly, 2 (In Chinese). 